\title{
DE KIERKEGAARD A FREUD: OBSERVACIONES SOBRE LA PSICOLOGÍA DEL MODERNO MALESTAR
}

\author{
Patricia C. Dip ${ }^{*}$ \\ doi:10.11144/Javeriana.uph34-68.kfop
}

\section{RESUMEN}

Los objetivos de este trabajo son: a) concebir El concepto de la angustia en términos de un desplazamiento de la filosofía del espíritu a la psicología integral del espíritu, que puede entenderse como un antecedente de la unificación del psiquismo operada por el psicoanálisis; b) indicar la pertinencia de considerar algunos planteos de Kierkegaard como el marco teórico a partir del cual clarificar la preocupación epistemológica manifestada por Freud desde fines del siglo XIX, en su esfuerzo por definir teóricamente el psicoanálisis; c) poner en evidencia el olvido histórico de Kierkegaard a la hora de presentar los vínculos de Freud con la filosofía.

Palabras clave: Søren Kierkegaard; Sigmund Freud; psicología; espíritu; psicoanálisis 


\title{
FROM KIERKEGAARD TO FREUD: COMMENTS ABOUT PSYCHOLOGY OF MODERN DISCONTENT
}

\author{
Patricia C. Dip
}

\begin{abstract}
The objectives of this work are: a) to conceptualize The Concept of Anxiety in terms of a shift in the philosophy of spirit towards the integral psychology of the spirit, which can be understood as an antecedent to the unification of the psyche brought about by psychoanalysis; b) to indicate the relevance of considering some of Kierkegaard's proposals as the theoretical framework on the basis of which understanding the epistemological concerns raised by Freud, in the late nineteenth century, in his effort to define psychoanalysis theoretically; c) to reveal the historical neglect of Kierkegaard when it comes to presenting Freud's links with philosophy.
\end{abstract}

Key words: Søren Kierkegaard; Sigmund Freud; psychology; spirit; psychoanalysis 


\section{Introducción}

LA OBRA DE KIERKEGAARD supone una relación crítica respecto del problema de la Modernidad. Si, por un lado, el filósofo danés desestima la autonomía de la razón kantiana, se enfrenta a la secularización y defiende el pathos de la individualidad frente al anuncio de la revolución, describe sin embargo el moderno malestar a partir de la utilización de una serie de categorías psicológicas, como son la melancolía, la angustia y la desesperación. Evidentemente, el impacto que la falta de eternidad provoca en la constitución de la subjetividad individual es una cuestión que está presente en sus escritos desde la publicación de $O$ lo uno o lo otro. En este libro la unidad sintética que otorga la personalidad ocupa un rol central en la plena comprensión de las categorías estéticas. De manera que el abordaje psicológico le permite al danés buscar una perspectiva de análisis en el límite de la racionalidad moderna.

La moderna subjetividad, desde Descartes a Hegel, implica la comprensión racional y sistemática del hombre; este debe hacerse patente a la racionalidad si desea comprenderse a sí mismo. Por el contrario, la imposibilidad de que el interesse se vuelva transparente a la razón es el punto de partida del análisis kierkegaardiano. Esto supone una decisión metodológica de retorno a Sócrates, -aplicándole el correctivo cristiano, es decir, dándole un sentido plenamente moral a su comprensión intelectual del hombre- y por lo tanto a la necesidad de subrayar el autoconocimiento, que si bien, después de Hegel, depende de la filosofía de la conciencia, no posee sentido especulativo, sino ético-religioso, pues no se basa únicamente en el yo abstracto sino en el yo que solamente deviene concreto a partir de una elección de carácter ético. Retomar la tradición socrática no implica sin embargo que el único movimiento que el pensamiento de Kierkegaard produce sea retrospectivo. Según lo entiendo, la filosofía espiritualista de Kierkegaard es el resultado de la combinación de tres problemáticas que atraviesan las discusiones teóricas presentes en su obra: el modelo moral del socratismo, la filosofía de la conciencia del idealismo y el cristianismo luterano de la interioridad. Si el discurso del pensador danés es significativo en el ámbito de la filosofía contemporánea, no se debe tanto al aparente sentido social del cristianismo de la segunda autoría, sino más bien a la introducción de la perspectiva psicológica de análisis introducida en la obra temprana. 
La discusión epistemológica introducida en El concepto de la angustia, señalando la distancia conceptual entre el paganismo y el cristianismo -distancia que el concepto de pecado expresa- indica justamente el movimiento progresivo de la propuesta del danés. Este movimiento progresivo convierte a Kierkegaard, en el ámbito epistemológico, en un antecedente del psicoanálisis freudiano. Si la filosofía primera es definida en términos inmanentes y metafísicos y la segunda filosofía toma como punto de partida la trascendencia e introduce la psicología de la angustia, con esta introducción anticipa la tercera filosofía: el psicoanálisis. En esta anticipación de carácter epistemológico no solo la categoría de angustia cumple un rol fundamental, sino también la de melancolía.

La psicología neumática o del malestar que Kierkegaard desarrolla en el período 1843-1849 implica un giro psicológico respecto de la tradición idealista alemana ${ }^{1}$. En este marco, la psicología es la disciplina privilegiada a partir de la cual es comprendido el moderno malestar. Para la psicología kierkegaardiana del espíritu la constitución de la subjetividad supone la superación de la inmediata relación entre cuerpo y alma, que el hombre comparte con el animal, por medio del espíritu que permite comprender lo inmediato en términos relacionales, que en Kierkegaard implican siempre la ambigüedad de la libertad, pues pueden dar como resultado tanto la transparente identidad del yo con el poder que lo fundamenta como su demoniaco oscurecimiento en la negación de este poder $^{2}$. El nexo entre el malestar descripto por Kierkegaard y el del que más tarde dará cuenta Freud en El malestar en la cultura y El porvenir de una ilusión es la distinción kantiana entre las esferas de la naturaleza y la libertad. La distancia que los separa depende justamente del diagnóstico de la enfermedad de la época moderna; para Kierkegaard el malestar depende de la falta de eternidad (Evighed) y para Freud, sin embargo, el carácter ilusorio de la falta de eternidad es justamente lo que conduce al malestar. De allí que Kierkegaard no evalúe

1 Este giro no es casual, sino que se vincula con la recepción de la obra de Johann Friedrich Rosenkrantz, Psychologie oder die Wissenschaft vom subjectiven Geist, publicada en Königsberg en 1837. El mismo Kierkegaard reconoce la influencia de Rosenkrantz en su análisis y tiene una valoración positiva del autor, aunque le critica que a menudo resulte ininteligible su modo de esquematizar (Kierkegaard, 1984a, p.182: SKS 4, p.447).

2 Sobre el concepto de demoníaco véase:Negre Rigol, 1988. 
positivamente la secularización de la cultura y que Freud, por el contrario, defienda la laicización de la misma.

\section{Cuestiones epistemológicas y categoriales}

LA CRÍTICA AL HEGELIANISMO iniciada en 1840 en Alemania da origen al programa teórico-práctico poshegeliano que definirá el horizonte filosófico europeo de la primera mitad del siglo XX, conformado por tres corrientes de pensamiento: el existencialismo, el marxismo y el psicoanálisis. Si bien Karl Löwith (1968) y Valls Plana (1994) dieron cuenta de las dos primeras corrientes, no se detuvieron en la última. Sin embargo, a pesar de la ambigua relación con la filosofía mantenida por Freud, tanto sus lecturas juveniles de Strauss y Feuerbach, como su comprensión de la filosofía en términos de un aparato cultural especulativo y por lo tanto abstracto, racionalista en los términos de la lógica formal, sistemático y conciencialista, emparentan sus preocupaciones teóricas con las de los filósofos poshegelianos ${ }^{3}$. En este marco, es posible establecer una línea de continuidad problemática entre la psicología neumática kierkegaardiana y el origen del psicoanálisis ${ }^{4}$.

Propongo que la discusión epistemológica planteada en la introducción a $E l$ concepto de la angustia puede ser leída en términos de anticipación de la tercera filosofía o psicoanálisis, que piensa la angustia sin necesidad de concebirla en relación con un telos dogmático. Esta diferencia es esencial a la hora de definir la distancia que media entre el modelo de secularización a partir del cual Kierkegaard concibe la Modernidad y el modelo de laicización utilizado por Freud para pensar la cultura contemporánea. Ella nos permite entender que mientras Freud intenta abandonar definitivamente el paradigma conciencialista de la filosofía moderna, que reduce el psiquismo a la conciencia, Kierkegaard aún se mueve en el seno de este paradigma.

3 Sobre la formación filosófica de Freud y su ambigua relación con la filosofía ver: Assoun, 1982.

4 En este sentido, no nos ocuparemos de las relaciones temáticas entre Kierkegaard y Freud, ya sea las que se pueden establecer a partir de la angustia o de los vínculos de ambos con el romanticismo, sino del desplazamiento de la filosofía del espíritu a la psicología del espíritu, como marco teórico filosófico de la discusión epistemológica de la que surge el psicoanálisis. 
En el período 1843-1849 la psicología kierkegaardiana, condicionada por el problema dogmático del pecado original, no se concentra solo en la categoría de la angustia, sino también en las de melancolía y desesperación. Cada una de ellas es utilizada con el objeto de presentar problemas específicos. La melancolía aparece ya en 1843 en O lo uno o lo otro, en el contexto de la descripción de las distintas concepciones de la vida estética, y hace referencia a un modo particular de concepción estética, la que se basa en el deseo y el gozo, representada por la figura histórica de Nerón, que pone de manifiesto tanto la ilimitada afirmación del propio deseo como el rechazo de la elección absoluta, que posibilita la constitución propiamente dicha de la personalidad. Un poco más tarde, en El concepto de la angustia, cuando Haufniensis intenta explicar el tránsito de la inocencia a la culpa, identifica la melancolía con la angustia y afirma que la primera puede utilizarse para describir el discurso de la primera parte de $O$ lo uno o lo otro, esto es: la concepción estética de la vida.

¿Por qué razón la melancolía permite describir la concepción estética de la vida y en qué consiste esta última? Si la psicología kierkegaardiana posee carácter neumático o espiritual, para definir la concepción estética será necesario determinar qué tipo de vínculo la estética permite establecer con la espiritualidad. O lo uno o lo otro parece indicar que la concepción estética de la vida se agota en la inmediatez. De lo cual se deduce una íntima relación entre la melancolía y los fenómenos inmediatos. La angustia, sin embargo, habiéndose introducido el telos del pecado original, implica ya una cierta ruptura con la inmediatez reflejada en la ambigüedad del espíritu que se encuentra soñando en el hombre en el tránsito de la inocencia a la culpa, e implica la introducción de cierta dialéctica, cuyo sentido pleno se hará manifiesto en la categoría de desesperación.

De modo que, si la constitución de la subjetividad es comprendida en términos de un progresivo desarrollo de la conciencia desde un nivel estético inmediato representado por la melancolía hasta un nivel religioso mediado (la introducción del yo como síntesis de cuerpo y alma en La enfermedad mortal) la angustia y por lo tanto la psicología propiamente dicha explicaría el tránsito de la inmediatez de la inocencia a la mediatez de la culpa o desesperación. En este sentido, la angustia cumple la función de categoría intermedia que Haufniensis le adjudica en 1844, pues permite describir el pasaje de la melancolía a la desesperación. En este marco, mientras la melancolía describe la inmediatez del 
instante del goce, la angustia describe el abandono de la inmediatez y en este sentido se vincula simultáneamente con la libertad y la ética, que le otorgan un telos a la concepción estética o melancólica. Por su parte, la desesperación supone la transformación o transfiguración de la ética en religión, porque no implica solamente el abandono del instante de la inmediatez, sino también la introducción de la eternidad como un término dialéctico que posibilita la mediación del espíritu y por lo tanto la auténtica afirmación del yo5.

\section{La psicología integral neumática en El concepto de la angustia}

\section{LA PSICOlOgía QUE TIENE in mente Haufniensis en El concepto de la angustia} surge en el seno de una confrontación entre dos modelos de ciencia que tanto Haufniensis como Constantino Constantius comparten. La denominamos como psicología integral neumática porque considera al hombre a partir de tres planos interrelacionados, el somático, el psíquico y el espiritual, el psíquico y el somático pensados a partir de una síntesis cuya unidad la ofrece el espíritu. Esta confrontación se produce entre un modelo pagano de ciencia, que piensa el saber en términos inmanentes y cuyo principio explicativo lo representa la reminiscencia, y el modelo cristiano, que entiende el saber en términos trascendentes y cuyo principio explicativo no lo constituye la reminiscencia sino la repetición ${ }^{6}$. Esta tajante confrontación no ofrece matices históricos ni progresiones, sino que se constituye en una suerte de presupuesto epistemológico que atraviesa El concepto de la angustia desde su introducción.

5 En relación con una lectura progresiva o procesual de la obra de Kierkegaard, Arne Grøn (1998) subrayó la necesidad de revisar la que dio en llamar "versión oficial” de la ética ofrecida por la interpretación que toma como eje la teoría de los estadios o esferas de la existencia y le contrapuso una explicación procesual de la ética. Esta nos permite entender la ética del amor al prójimo de 1847, como el contenido de la segunda ética esbozada en El concepto de la angustia.

6 El concepto de repetición es introducido hacia el final de un opúsculo inconcluso de autor desconocido, escrito probablemente entre 1842-1843, llamado Johannes Climacus o el dudar de todas las cosas y se convierte más tarde en el título de la obra de Constantino Constantius: La repetición. El tema de Johannes Climacus es el sentido del moderno escepticismo y la posibilidad de filosofar sin supuestos, y no hay indicios que indiquen que su autor compartiera la distinción entre reminiscencia y repetición que Constantino y Haufniensis sostienen, ya que la introducción de la noción de repetición solo se esboza hacia el final del opúsculo y sin ninguna referencia explícita a la filosofía antigua. 
En el marco de una discusión en torno al nuevo ordenamiento de las disciplinas, necesario para dar cuenta del pecado original, que en tanto concepto no posee domicilio propio en ninguna ciencia, Haufniensis postula una nueva ciencia:

la nueva ciencia [den nye Videnskab] empieza con la dogmática, exactamente en el mismo sentido en que la ciencia inmanente [den inmanente Videnskab] comienza con la metafísica. Aquí la ética encuentra nuevamente su lugar como la ciencia que tiene la conciencia dogmática de la realidad como tarea para la realidad. (Kierkegaard, 1984a, p. 44; traducción propia) ${ }^{7}$

La ética a la que ahora hace referencia es de un orden distinto de la anterior. La primera no lograba explicar la pecaminosidad del individuo, que se diluía en el pecado de toda la humanidad y volvía enigmáticas las dificultades morales ${ }^{8}$. En este punto, la intervención de la dogmática ayuda a resolver el problema con la introducción del pecado original.

La nueva ética presupone la dogmática y con ella el pecado original; y gracias a ella ya puede explicar el pecado del individuo, al mismo tiempo que propone la idealidad como tarea. Sin embargo, no hay aquí un movimiento de arriba a abajo, sino de abajo a arriba. (Kierkegaard, 1984a, p. 44; SKS 4, p. 328)

El movimiento de abajo hacia arriba al que hace referencia el pseudónimo implica que la segunda ética no toma como punto de partida la pura idealidad sino la realidad, introducida por medio del salto que introduce el pecado. En este marco, los límites de la psicología son precisos: esta no puede ocuparse de la realidad, que no es su objeto propio, sino de la posibilidad real de la angustia en la conciencia. Por su parte, la dogmática es la disciplina que tiene como objeto la posibilidad ideal del pecado. De este modo, a partir de una nueva configuración de las ciencias, se vislumbra la aparición de una nueva disciplina, que es la psicología.

7 Teniendo en cuenta que la lengua danesa no es de uso corriente, ofreceremos las referencias de la edición danesa conjuntamente con las de la edición española con la que contamos hasta el momento, e incorporaremos nuestra propia traducción en los casos en los que la traducción de la edición española sea confusa o equívoca. Para la edición danesa usaremos la sigla SKS e indicaremos el tomo correspondiente.

8 La cuestión aquí es que la ética pagana no poseía los conceptos necesarios para explicar el pecado original, lo que no deja de ser una manera de forzar la moral antigua a responder al modelo posterior del cristianismo. En algún sentido, la misma violencia comete Anti-Climacus contra Sócrates cuando habla del "concepto socrático de pecado". 
A continuación, Haufniensis hace referencia a la comprensión aristotélica de la metafísica como filosofía primera -que abarcaba también elementos teológicos, lo que era lógico en el paganismo, aunque ya no lo es una vez introducido el cristianismo en la historia- con el objeto de conservar el concepto de filosofía primera y contraponerlo al de secunda philosophia, propio de la ciencia nueva que el pseudónimo introduce.

Dejando de lado esta ambigüedad, podría conservarse la denominación de filosofia primera, y entender por ella la totalidad científica que puede llamarse pagana [den ethniske] y cuya esencia es la inmanencia o, dicho en griego, la reminiscencia [Erindrigen] y entender por secunda philosophia aquella cuya esencia es la trascendencia o la repetición [Gjentagelesen]. (Kierkegaard, 1984a, p. 44-45; SKS 4, p.328-329)

Una vez introducida esta contraposición, se aclara que el concepto de pecado no puede ser tratado propiamente por ninguna ciencia; solamente la segunda ética es capaz de dar cuenta de sus manifestaciones, aunque no de su origen, y la psicología, aunque no pude tratarlo, puede sin embargo dar cuenta de la posibilidad real del pecado ${ }^{9}$.

En este sentido, esta ciencia puede ocuparse y estar ocupada con el problema de cómo es posible que surja el pecado, pero no del hecho de su existencia. Y, en su interés psicológico, esta ciencia puede llevar tan lejos el problema que aparezca en su horizonte como si el pecado existiera, si bien el hecho de que exista en realidad es otro asunto completamente distinto. (Kierkegaard, 1984a, p. 45; SKS 4, p. 329)

El límite de la psicología, por lo tanto, se encuentra en la descripción de la posibilidad real del pecado. La pretensión de convertir en realidad esa posibilidad subleva a la ética y es blasfemia para la dogmática, porque "la libertad nunca es posible; tan pronto como existe, es real” (Kierkegaard, 1984a, p. 46; SKS 4, p. 329). Solamente la posibilidad del pecado es objeto, hasta cierto punto, de la psicología. Es decir, como se pondrá de manifiesto a lo largo de la obra, la

9 Para una discusión sobre las categorías de idealidad, realidad y posibilidad en relación a las ciencias que se ocupan de describir el fenómeno del pecado, véase: González, 2001. 
psicología solamente puede describir el estado o condición (Tilstand $)^{10}$ en que se encuentra el individuo tanto antes como después de la caída, a saber: la angustia. Esta categoría no puede ser comprendida independientemente de su relación con la libertad, como quedará explicitado en el capítulo IV, cuando se comprenda la falta de libertad a partir del concepto de demoníaco.

A continuación, si bien Haufniensis acepta la comprensión hegeliana de la psicología en términos de espiritu subjetivo, exige que esta se transforme en espiritu absoluto, y que el espíritu no se entienda de modo metafísico sino dogmático, dado que el desarrollo de las distintas figuras de la conciencia no conduce ya al necesario despliegue del saber absoluto, sino a la ambigua asunción de la libertad individual. $\mathrm{Al}$ no ser planteada la libertad en el terreno metafísico, esta ya no se identifica con la necesidad. De lo que se trata es de dejar de pensar la libertad de manera abstracta y de comenzar a pensarla de manera concreta, como el problema del tránsito del estado de inocencia al estado de culpabilidad. Esto supone un tránsito de la filosofía del espíritu a una suerte de psicología del espíritu cuyas posibilidades de desarrollo dependen de la aceptación del dogma del pecado original.

Teniendo en cuenta que la aparición de la angustia explica el pasaje del estado de inocencia al de la culpa, podría parecer que la misma desaparece una vez que se ha cometido efectivamente una falta. Sin embargo, esto no es así pues la eliminación de la angustia conllevaría la erradicación de la libertad, puesto que lo que está en juego a la hora de explicar la aparición del estado de angustia en el individuo es justamente su relación con la libertad. En este sentido, la psicología es introducida con el objeto de evitar la explicación abstracta del problema de la libertad que ofrece, según lo entiende Haufniensis, la noción de libre albedrío. La angustia da cuenta de la relación concreta que el individuo establece con la libertad, y una vez cometido el pecado la angustia no es eliminada, sino que cambia de objeto. Si en la inocencia la angustia tenía como objeto la nada, en la culpa su objeto pasa a ser algo real, pues ha sido introducida de manera concreta la diferencia entre el bien y el mal.

10 En el capítulo IV, Demetrio G. Rivero traduce la palabra danesa Tilstand indistintamente por estado o situación. Nos parece mejor traducirla por estado o condición para evitar la posible referencia a algo exterior, una situación, que pueda afectar al individuo, porque la discusión gira en torno al estado interior en que el individuo se encuentra o bien antes de caer en el mal o bien después de haber caído en él. 


\subsection{LA DIALÉCTICA DE LA LIBERTAD COMO OBJETO DE LA PSICOLOGÍA}

NI EL BIEN NI EL PECADO admiten definición alguna; al primero se lo identifica con la libertad, entendida en la línea kantiana, como un postulado de la razón que no puede demostrarse racionalmente pero debe presuponerse prácticamente, y lo mismo sucede con el pecado: "el pecado se supone a sí mismo como le pasa también a la libertad [...] y ni el uno ni la otra pueden explicarse por algo previo [... ] La libertad es infinita y no brota de nada" (Kierkegaard, 1984a, p. 144; SKS 4, p. 414)

En el contexto de la descripción del fenómeno de la libertad se aclara que el objeto de la psicología es la angustia, en el marco de la historia individual, cuyo progreso no se produce de manera necesaria sino por medio del salto que explica el tránsito de un estado a otro estado. "A cada uno de estos saltos le precede, como su máxima aproximación psicológica, un estado. Este estado es el objeto de la psicología. En todo estado está presente la posibilidad y, por consiguiente, la psicología" (Kierkegaard, 1984a, p. 145; SKS 4, p. 415 traducción propia).

En el capítulo IV de El concepto de la angustia se reafirma la idea de que la angustia es objeto de la psicología y se aclara que sigue siéndolo a pesar de que haya sido cometido el pecado. La angustia no es entonces eliminada, sino que se conserva como el modo de explicar el estado en el que se encuentra el individuo tanto antes como después de haber realizado efectivamente una acción. Cada vez que el pecado se produce, no surge como resultado o consecuencia del pecado original, sino que es resultado del salto. La repetición del pecado no supone la anulación de la angustia; esta persiste como indicador del estado en el que se encuentra la conciencia individual. La psicología que Haufniensis tiene in mente, al presuponer el dogma del pecado original, se concentra en las posiciones psicológicas de la libertad frente al pecado, que se identifican con lo que el pseudónimo denomina estados psicológicos aproximativos. En el marco de la historia de la filosofía, la discusión planteada implica la asunción de la tesis kantiana que concibe la libertad como un postulado, pero no ya en el marco de la razón práctica, puesto que "en ningún caso pretenden ser explicaciones éticas del pecado" (Kierkegaard, 1984a, p. 150; SKS 4, p. 420).

La psicología es introducida justamente con el objeto de subrayar la imposibilidad de que el pecado sea objeto de explicación teórica y, a su vez, al ser 
presentado el mal en su íntima ligazón con la libertad, esta última se transforma también en objeto de aproximación psicológica. Si bien el marco general de la discusión del problema del mal es heredado de la tradición agustiniano-cartesiana y, por lo tanto, si el hombre peca, es por su propia culpa; lo que Haufniensis introduce de novedoso en este esquema es la idea de que el liberum arbitrium no es más que la postulación abstracta de la libertad y resulta por lo tanto insuficiente para explicar el pecado del individuo particular. La categoría de la angustia es introducida con el objeto de explicar el problema concreto de la libertad. El análisis de la libertad es presentado en términos dialécticos, por lo tanto, el pecado es entendido como pérdida o negación de la libertad. Ahora bien, la libertad perdida también ofrece dos direcciones, o bien la esclavitud del pecado -que se describe como una relación forzada con el mal y que en el apartado titulado "La angustia ante el bien" permite dos alternativas, el remordimiento o el arrepentimiento- o bien la relación forzada con el bien, o lo demoníaco, donde la libertad ha sido negada. Si en la inocencia la angustia del individuo se relacionaba con la posibilidad de la libertad, en la culpa demoníaca la angustia se vincula con la pérdida de la misma. La esclavitud de lo demoníaco se opone a la inocencia, pues esta tiende hacia la libertad, mientras que "lo demoníaco es la no-libertad (Ufribeden) que quiere clausurarse en sí misma” (Kierkegaard, 1984a, p. 156; SKS 4, p. 424).

Al describir lo demoníaco como un fenómeno que no pertenece a la esfera de la naturaleza sino a la de la libertad -o más bien a su negación-, se explica, por un lado, la pertenencia del mismo a la esfera espiritual y, por el otro, la relación de la psicología neumática con la sociedad y la época. La idea de pensar el lenguaje, en su función comunicativa, como expresión de la personalidad que busca la libertad (y al definirse el bien como la libertad, lo que el individuo intenta a través de la comunicación es deshacerse del mal) implica que las relaciones sociales son utilizadas como criterio determinante de la individualidad. Es decir, la psicología no puede operar a partir del supuesto de que los individuos son átomos aislados ${ }^{11}$. Son, por lo tanto, objeto de la psicología tanto los individuos como las relaciones sociales que estos establecen, pues el entorno define los caracteres de la personalidad individual.

11 En la misma línea puede leerse Psicología de las masas y análisis del yo. Allí, Freud explica la necesidad de poner en diálogo la psicología del yo con la psicología social o colectiva, teniendo en cuenta que ningún individuo se comprende independientemente de las relaciones sociales que entabla con los demás, sean estos los miembros de la familia o los de la sociedad civil. 
Esto explica que "la misma sociabilidad nos confiera una certeza de la presencia de lo demoníaco” (Kierkegaard, 1984a, p. 172; SKS 4, p. 438).

\subsection{LO DEMONÍACO COMO EXPRESIÓN DEL CARÁCTER INTEGRAL DE LA PSI-} COLOGÍA Y COMO CATEGORÍA PSICOLÓGICA DE LA CRÍTICA EPOCAL

Considero el Concepto De det Demoniske en dos direcciones: como expresión del sentido integral de la psicología y como recaída epocal en lo cómico. Es decir, el análisis psicológico conlleva como consecuencia la crítica a su propia época, o lo que es lo mismo, la crítica de Kierkegaard a su época es elaborada en términos psicológicos. La psicología a la que denominamos integral concibe lo demoníaco como un desorden en las tres esferas que constituyen lo propiamente humano, la somática, la psíquica y la espiritual.

A la hora de introducir el concepto de lo demoníaco Haufniensis recurre al Nuevo Testamento (Mateo VIII, 28-34, Marco V, 1-20, Lucas VIII, 26-39, Lucas XI, 14) con el objeto de mostrar que lo demoníaco solo llega a manifestarse cuando Cristo hace acto de presencia, es decir, al ser acosado por el bien. De allí que lo defina como angustia ante el bien. La angustia es una categoría que describe el estado en el que la personalidad se encuentra a la hora de actuar y no es posible eliminarla por dos razones: por un lado, por su referencia inmediata a la libertad humana y, por el otro, por su referencia a la esfera de la vida activa. Eliminar la angustia supondría negar la libertad y conjuntamente con ella la acción humana que es de orden futuro. Si bien no es posible erradicarla, sí lo es educarla por medio de la fe.

La angustia puede expresarse tanto en el mutismo como en el grito y el bien significa la reintegración del esclavo del mal a la esfera de la libertad. Sin embargo, la esclavitud del pecado no se identifica con lo demoníaco. Cuando el hombre peca y permanece en el pecado, aparecen ante él dos posibilidades: la angustia ante el mal o la angustia ante el bien. El primer tipo de angustia es provocada por la posibilidad de retomar nuevamente el camino del mal, una vez que el pecado ha sido introducido, pero el individuo que en este caso se angustia "quiere el bien".

La descripción de la angustia ante el mal pertenece a la esfera de la psicología, en la que, una vez introducido el pecado en tanto posibilidad abolida y realidad injustificada, los estados de remordimiento y arrepentimiento son concebidos en términos de estados psicológicos aproximativos que no pueden abolir el 
pecado, es decir, no logran tornarse en libertad, sino que quedan reducidos a mera posibilidad. Una vez que el pecado ha sido cometido, trae consigo una consecuencia, y el modo en que la angustia se relaciona con ella es objeto de la psicología pues no hace referencia a la realidad del pecado sino a su posibilidad. "Por mucho que se haya hundido un individuo, todavía puede hundirse más, y este 'puede' es el objeto de la angustia" (Kierkegaard, 1984a, p. 145; SKS 4, p. 416).

Sin entrar en el estudio de la relación cuerpo-alma, ni en la tradición helénica ni en la alemana, Haufniensis asume que el cuerpo es órgano del alma y también del espíritu. Si la relación de subordinación del cuerpo se modifica, la rebeldía corporal conduce a la libertad a confabular con el cuerpo contra sí misma y como consecuencia la libertad es negada dando lugar a la aparición de lo demoníaco. Si en la relación cuerpo-alma aparece algún desorden, pero la libertad no se rebela, habrá angustia, pero esta será angustia por causa del mal y no angustia por causa del bien.

Haufniensis distingue tres modos de enfocar lo demoníaco, desde el punto de vista estático-metafísico, por la vía del enjuiciamiento ético, y desde el punto de vista terapéutico, con el objeto de señalar que estos distintos puntos de vista fueron posibles debido al carácter ambiguo del fenómeno, que no es solamente físico como lo supone la perspectiva terapéutica que interna al paciente para evitar la propagación del mal. Por el contrario, lo demoníaco pertenece a las tres esferas (somática, psíquica y espiritual) y, como consecuencia de esta perspectiva de análisis, la desorganización en una esfera repercute en las otras dos. La angustia es un fenómeno universal cuyas huellas se encuentran en todo hombre, en tanto y en cuanto este es entendido como pecador. Ahora bien, mientras la angustia en general es el objeto propio de la psicología, la angustia ante el bien (lo demoníaco) permite establecer nexos con la época y convertirse a partir de los mismos en una suerte de diagnóstico psicológico del malestar epocal.

La interioridad subjetiva, cuyo telos es la libertad que se ve oscurecida por la culpa, es el objeto de la psicología neumática que encuentra en la función comunicativa del lenguaje el locus de lo social. El interés por la sociabilidad como lugar de expresión de la apertura individual posee límites precisos; es en la sociedad donde lo demoníaco rechaza la esclavitud de su ensimismada conciencia y recupera la posibilidad. Sin embargo, no hay nada más allá del escenario de la apertura que le interese a Haufniensis a la hora de describir la función que cumple el 
vínculo con los demás hombres. De allí que la psicología neumática se constituya en la herramienta que, haciendo hincapié en el camino de la libertad individual sea utilizada para dar cuenta del malestar epocal, basado en la ciencia entendida en términos de un progreso cuantitativo cuya obsesión por la verdad la aleja de la certeza de la interioridad, esto es, de la libertad que constantemente se gana a sí misma como posibilidad. La caracterización de la época presente se resume en la falta de certeza e interioridad, lo que permite deducir que esta privilegia la exterioridad. La recaída en lo cómico se identifica entonces con la exterioridad del tiempo presente. La época trágica, determinada por el inquebrantable destino, es reemplazada por una época que, habiendo descubierto el camino de la libertad, lo niega.

No es sorprendente que el diagnóstico epocal de la psicología neumática sea una suerte de pesimismo respecto de la posibilidad de pensar la libertad en un terreno que no sea el de la conciencia. Sin embargo, aun cuando el psicoanálisis de Freud pretenda dejar atrás la filosofía de la conciencia, piensa la cultura en términos de opresión de la vida instintiva y no se aleja finalmente del pesimismo de Haufniensis. Todo pareciera indicar que, si el punto de partida del análisis psicológico es el individuo, más allá de los términos en que el psiquismo sea concebido, el punto de llegada solo aporta un método para pensar la sociedad (Kierkegaard) y la cultura (Freud), o bien como el ámbito de la apertura individual o bien como lo contrario, es decir, un ámbito hostil para la expresión de la vida instintiva, pero jamás como el ámbito donde la subjetividad logra satisfacer de manera plena su deseo de autonomía. Tal vez ello explique el rechazo de Kierkegaard a las revoluciones burguesas y el de Freud al incipiente socialismo que para muchos significaba el nacimiento de una nueva cultura.

\subsection{LA PSICOLOGÍA NEUMÁTICA O DE LA DOBLE VOLUNTAD}

EN EL CONCEPTO DE LA ANGUSTLA comienza a delinearse una suerte de "teoría de la doble voluntad", que se mantiene en La enfermedad mortal. El problema del pecado y su relación con la libertad adquiere en la segunda obra un sentido más radical, al ser incluida la noción for Gud (delante de Dios), cuya consecuencia es la cristianización de los fenómenos éticos y, por lo tanto, la aparición de la noción de desesperación. Lo que nos importa destacar aquí es el tránsito de la filosofía de la conciencia, propia de la filosofía moderna, desde Descartes a Hegel, a una 
psicología de la doble voluntad presentada por Kierkegaard, debido a que el tránsito de la primera a la segunda conforma el horizonte teórico que permite alumbrar la discusión epistemológica a la que se enfrenta el psicoanálisis en sus orígenes. En suma, la progresión conceptual que permite concebir el psicoanálisis desde la perspectiva de análisis de la filosofía es la siguiente, de la crítica a la presuntamente abstracta filosofía de la conciencia a la concreta psicología neumática o de la doble voluntad.

El fenómeno demoníaco es descrito haciendo hincapié en la voluntad. El individuo ensimismado posee dos voluntades, una débil que lo impulsa a salir de su cerrazón, la voluntad de la libertad ${ }^{12}$, y otra fuerte que lo hace aferrarse a ella.

El criterio decisivo sobre si el fenómeno es o no demoníaco nos lo dará la posición que el individuo mantenga respecto de la apertura, es decir, si quiere o no quiere penetrar y asumir con toda su libertad aquel hecho funesto.

(Kierkegaard, 1984a, p.162; SKS 4, p. 429-430)

Un ejemplo de esto lo ofrece quien, en circunstancias excepcionales, comete una acción que apenas recuerda y le impide reconocerse a sí mismo.También en La enfermedad mortal la facultad de la voluntad es destacada, por un lado, como un descubrimiento cristiano, que permite diferenciar el cristianismo de la inocente mentalidad pagana, y por otro, como la facultad que conduce los impulsos más bajos del hombre y oscurece el conocimiento que el entendimiento ofrece. En el capítulo II de la segunda parte el socratismo es descrito en términos de imperativo categórico intelectual por considerar que entender lo justo implica realizarlo de manera inmediata. Sócrates carece justamente de la categoría de voluntad que es la que explica que la comprensión de lo justo no supone su inmediata realización, para realizar lo justo es necesario querer hacerlo. A su vez, la no realización de lo justo supone el no querer realizarlo. Aunque se comprenda intelectualmente lo justo, si la voluntad oscurece esta comprensión, entonces el bien no se realiza. Este, según Anti-Climacus, es un descubrimiento cristiano.

Mientras en El concepto de la angustia la voluntad puede conducir al hombre en la dirección de la libertad, en La enfermedad mortal la voluntad es la facultad que indica la dependencia de la libertad humana de una fuerza superior a ella

12 "La voluntad de la libertad, por muy débil que ella sea, nunca deja de estar presente en todas las contradicciones interiores del yo” (Kierkegaard, 1984a, p. 178; SKS 4, p. 443). 
misma. El desesperado es aquél que quiere permanecer en el mal, ya sea negando el propio yo al no querer ser si mismo, o afirmándolo queriendo ser sí mismo, sin ser capaz de entregarse libremente al poder que lo fundamenta y lo liga a la eternidad. Tanto el querer como el no querer ser sí mismo oscurecen la transparencia de la relación con el fundamento. De allí que la voluntad sea una facultad que entorpece finalmente la autorrealización del yo en el sentido de desconocer la dependencia del sí mismo de algo que le es ajeno.

A su vez, en La enfermedad mortal la desesperación es entendida como una enfermedad del espíritu cuyo sentido es universal:

nadie puede vivir, ni ha vivido jamás fuera de la cristiandad sin que sea desesperado; ni tampoco se librará nadie de serlo, aunque viva dentro de la cristiandad, si no es un cristiano auténtico, pues quien no lo sea íntegramente, siempre tendrá algo de desesperado. (Kierkegaard, 1984b, p. 49; SKS 11, p. 138)

La universalidad de la desesperación, que podría hacerse extensiva a la de la neurosis, es definida a partir de una analogía con la enfermedad física o somática. Mientras la tarea del médico es descubrir, independientemente de lo que dice el paciente de su propio estado, cuál es su verdadera condición, "en la misma situación se encuentra también el psicólogo respecto de la desesperación” (Kierkegaard, 1984b, p. 51; SKS 11, p. 139-140).

Así como el médico conoce las enfermedades y sabe si el paciente está o no enfermo, el psicólogo conoce la desesperación y por eso no se contenta con lo que el individuo pueda decir sobre si está o no desesperado. Sin embargo, al contrario de lo que sucede con la enfermedad física, el pasaje de la salud a la enfermedad o viceversa, no se produce de la misma forma. Un médico que tiene pruebas del estado de salud de un paciente puede decir que antes estaba sano y ahora está enfermo. Con la desesperación sucede algo distinto; su aparición solo corrobora que el que la padece ya estaba desesperado con anterioridad. Y que ha sido un desesperado a lo largo de toda su vida. Por el contrario, si alguien tiene fiebre, no se deduce de ello que la haya tenido durante toda su vida.

Pero la desesperación es un fenómeno del espíritu, algo que se relaciona con lo eterno y que, por consiguiente, contiene algo eterno en su dialéctica [...]. La desesperación no solo es dialéctica de una manera completamente distinta a la que lo es cualquier otra enfermedad, sino que también todos sus síntomas son dialécticos. (Kierkegaard, 1984b: p. 52; SKS 11, p. 141) 
$\mathrm{Al}$ contrario de lo que sucede con la enfermedad en sentido somático o físico, el malestar es dialéctico, de tal modo que el no haberse sentido jamás enfermo puede ser síntoma de la desesperación, de la misma manera que sucede con la neurosis, a la que, de haberla conocido, Anti-Climacus hubiera considerado como dialéctica, de un modo especial.

\section{La génesis del psicoanálisis: la sombra de una presencia}

Es SUGESTIVO QUE EN los análisis sobre el vínculo entre Freud y la filosofía se haga referencia a las clases de Brentano, a la influencia de Nietzsche en la formulación freudiana del concepto de inconsciente (Assoun, 1980), al horizonte teórico del pesimismo de Schopenhauer, para pensar la función de la cultura en el esquema analítico freudiano; en la presencia de Kant en la confrontación del concepto de inconsciente con las condiciones temporales establecidas en la "Estética trascendental" para pensar el sentido interno; y que la figura de Kierkegaard no aparezca ni siquiera detrás del oscuro escenario de la génesis del pensamiento psicoanalítico ${ }^{13}$.

Sin embargo, existe una llamativa similitud entre la discusión epistemológica desarrollada en El concepto de la angustia y la búsqueda freudiana de definición del psicoanálisis llevada a cabo desde fines del siglo XIX. Dado que el pecado no posee domicilio propio en ninguna ciencia, Haufniensis introduce una categoría paralela, la de la angustia, con el objeto de describirlo. Cuando Freud busca definir el sentido del psicoanálisis y llama la atención acerca de que el inconsciente que tiene in mente no es el inconsciente de los filósofos, coloca al psicoanálisis entre la filosofía y la medicina, es decir, reconoce que este no tiene domicilio propio en ninguna ciencia. Y, por otra parte, se enfrenta al pensamiento abstracto y sistemático de la tradición filosófica, a partir de la incorporación de la base empírica. A su vez, si Kierkegaard recoge la noción de angustia como una categoría límite o intermedia, que permite aprehender un fenómeno cuya

13 Veáse Assoun (1982) Tauber (2014). La edición francesa de Assoun data de 1977 y la edición inglesa de Tauber del año 2010. Citamos dos análisis de la relación de Freud con la filosofía de épocas diferentes, como paradigmáticos del olvido de Kierkegaard. En 1980 Assoun publica Freud et Nietzsche. Esta obra es una profundización del trabajo publicado en 1977. 
naturaleza no es definida, lo mismo sucede con la indeterminación inicial de los términos básicos (Grundbegriffe) del psicoanálisis.

A pesar de que las relaciones de Freud con la filosofía hayan sido ambiguas, y el vínculo con Kierkegaard aparentemente inexistente, los planteos fenomenológicos del pensador danés, si bien se originan en el marco conceptual de la filosofía de la conciencia, implican un desplazamiento de la filosofía a la psicología de la angustia que alumbra justamente la posterior discusión psicoanalítica. Si bien la psicología de Haufniensis manifiesta una mirada crítica respecto al progreso científico que la diferencia del origen del proyecto freudiano, este comparte algunos aspectos ya presentes en la psicología neumática, a saber: la necesidad de desplazar el análisis de los fenómenos psicológicos, la angustia, la desesperación y la neurosis, del plano somático al psíquico, por un lado, y la universalización de estos fenómenos de la esfera patológica a la esfera de la normalidad. Al mismo tiempo, el origen del psicoanálisis supone la conversión de la catarsis -el poder liberador de la palabra en Haufniensis- en terapéutica.

Es posible establecer una analogía entre el tratamiento de lo demoníaco (un tipo de angustia), entendido como un fenómeno cuya naturaleza no es exclusivamente somática -con la consecuente universalización de la angustia a todos los hombres-y la comprensión del fenómeno de la neurosis que exigió que Freud venciera la impotencia médica. "El psicoanálisis nació en un terreno estrictamente delimitado. Originalmente solo conocía un fin: el de comprender algo de la naturaleza de las enfermedades nerviosas llamadas 'funcionales', para vencer la impotencia médica de hasta entonces en cuanto a su tratamiento" (Freud, 1988, p. 2729). Los neurólogos de la época, formados en la sobreestimación de los hechos físicoquímicos y patológico-anatómicos, se inclinaban por pensar en términos de una vinculación exclusiva entre ciertas funciones y determinadas partes del cerebro. "Con el factor psíquico no sabía qué hacerse" (Freud, 1988, p. 2729).

Los neurólogos abandonaban el factor psíquico a los filósofos, místicos y curanderos a la vez que como terapia específica de los estados nerviosos se aconsejaba la electricidad. Entre 1880 y 1890 se produce un viraje decisivo debido a la incorporación en la ciencia médica de los fenómenos del hipnotismo, cuya consecuencia fue el reconocimiento de la autenticidad de tales fenómenos. Este paso condujo al convencimiento de que ciertas alteraciones somáticas eran el resultado de influencias psíquicas, por un lado, y a la postulación de procesos anímicos 
inconscientes, por el otro. "Lo inconsciente era ya, tiempo atrás, como concepto teórico, objeto de discusión entre los filósofos; pero en los fenómenos del hipnotismo se hizo por vez primera corpóreo, tangible y objeto de experimentación" (Freud, 1988, p. 2729). El hipnotismo permite entonces dar el primer paso en la formulación de la ciencia nueva. "Tanto en el sentido teórico como terapéutico, el psicoanálisis administra una herencia que el hipnotismo le transmitió” (Freud, 1988, p. 2730).

Si bien en un primer momento la hipnosis resultó ser un medio auxiliar para el estudio de las neurosis y especialmente de la histeria -el mismo Freud reconoce la importancia de Breuer, quien en 1881 logró estudiar y recuperar a una enferma de histeria con ayuda del hipnotismo-, el abandono de la hipnosis fue un segundo paso decisivo en la génesis del psicoanálisis, ya que permitió la introducción de la catarsis como antecedente inmediato del psicoanálisis. En Estudios sobre la histeria (1895), Freud y Breuer intentaron integrar sus experiencias en el marco de una teoría que oficiaba de fundamento de las mismas.

Esta teoría afirmaba que el síntoma histérico nacía cuando el afecto de un proceso anímico intensamente afectivo era desviado de la elaboración consciente normal y encaminado así por una ruta indebida. En el caso de la histeria, dicho afecto se resolvía en inervaciones somáticas inhabituales (conversión), pero podía ser dirigido en otro sentido y descargado por medio de la reviviscencia del suceso correspondiente durante la hipnosis (derivación por reacción). A este procedimiento le dimos el nombre de catarsis (limpieza, liberación del afecto represado). (Freud, 1988, p. 2731)

Poco después de esta publicación, Freud deja de trabajar con Breuer. "Las innovaciones técnicas por mí introducidas y mis descubrimientos hicieron del procedimiento catártico el psicoanálisis" (Freud, 1988, p. 2731). El paso decisivo fue el abandono del hipnotismo por dos razones; había muchos pacientes a los que Freud no lograba hipnotizar y, por otra parte, los resultados del tratamiento se revelaban poco duraderos y dependientes de la relación personal del médico con el paciente. Este abandono significó un nuevo comienzo y la búsqueda de otra técnica auxiliar que fue la asociación libre. "La libre asociación y el arte interpretativo lograban el mismo resultado que antes el hipnotismo" (Freud, 1988, p. 2732). 
El momento decisivo, tanto del origen del psicoanálisis como del tránsito de la explicación de los fenómenos patológicos a los normales, lo constituye la publicación de La interpretación de los sueños (1900).

A partir de la interpretación de los sueños, reunió el psicoanálisis una doble significación: no era ya solo una nueva terapia de la neurosis, sino también una nueva psicología; aspiraba a ser tenida en cuenta, no solo por los neurólogos, sino por todos los hombres consagrados a las ciencias del espíritu ${ }^{14}$. (Freud, 1988, p. 2735)

En Las resistencias contra el psicoanálisis (1925), al describir las distintas actitudes tomadas frente a su descubrimiento, Freud considera que es comprensible que en una época materialista los médicos y los psiquiatras redujeran los cuadros patológicos a factores patógenos somáticos, anatómicos o químicos. Sin embargo, era de esperar que una nueva doctrina fuera bien recibida por los filósofos, ya que estos solían explicar el universo a partir de conceptos abstractos. Esta esperanza resultó vana, pues el psicoanálisis tropezó aquí con un nuevo obstáculo:

lo psíquico de los filósofos no equivalía a lo psíquico del psicoanálisis. En su mayoría los filósofos solo califican de psíquico a lo que es un fenómeno de consciencia; para ellos, el mundo de lo consciente coincide con el ámbito de lo psíquico. Cuanto pueda suceder, fuera de esto, en el 'alma', tan difícil de captar, lo adjudican a las precondiciones orgánicas o a los procesos paralelos de lo psíquico. En términos más concisos, el alma no tiene otro contenido, sino los fenómenos conscientes, de modo que la ciencia del alma, la psicología, mal puede tener otro objeto. Tampoco el profano piensa de distinta manera. (Freud, 1988, p. 2803)

El filósofo comparte el punto de vista del sentido común, es decir, no acepta que lo psíquico es inconsciente y que la conciencia solamente es una cualidad que puede agregarse o no a cada acto psíquico, sin que su ausencia lo afecte. La hegemonía del paradigma conciencialista provoca un efecto paradójico, pues el organicismo continúa siendo su destino normal.

14 En su Autobiografía sostiene Freud (1988): "por uno de aquellos desarrollos contra cuyo resultado es inútil resistirse ha acabado por integrar varios sentidos la palabra psicoanálisis. Originariamente no constituía sino el nombre de un método terapéutico especial, pero ahora ha llegado a convertirse en el nombre de una ciencia, de la ciencia de lo psíquico inconsciente" (p. 2797). 
En la introducción a El concepto de la angustia queda claro que para que se produzca el nacimiento de una nueva ciencia es necesario plantear una discusión epistemológica, que en el caso de Haufniensis da como resultado la reacomodación de las ciencias que pueden dar cuenta del pecado original, de modo tal que la metafísica y la lógica son desplazadas para darles lugar a la dogmática y la psicología. En el caso de Freud, la discusión epistemológica lo conducirá a pensar el psicoanálisis como un tipo de Naturwissenschaft, que lo obliga a ubicarlo entre la filosofía y la medicina. El psicoanálisis no se reduce a pura biología, pero tampoco queda restringido al ámbito de la especulación filosófica, pues posee una base observacional ${ }^{15}$.

También el analista se niega a declarar qué es lo inconsciente, pero al menos puede señalar un sector fenoménico cuya observación le impuso la aceptación de lo inconsciente. El filósofo, que no conoce otra forma de observación más que la de sí mismo, no puede seguir al analista por este camino. Así el psicoanálisis solo saca desventajas de su posición intermedia entre la medicina y la filosofía. El médico lo considera como un sistema especulativo y se niega a creer que, como cualquier otra ciencia de la Naturaleza, se base en una paciente y afanosa elaboración de hechos procedentes del mundo perceptivo; el filósofo, que la mide con la vara de sus propios sistemas artificiosamente edificados, considera que parte de premisas inaceptables y le achaca el que sus conceptos principales -aún en pleno desarrollo- carezcan de claridad y precisión. (Freud, 1988, p. 2803-2804)

15 Según Haufniensis “a un observador, supuesta la debida atención a sí mismo, le son más que suficientes cinco hombres, otras cinco mujeres y diez niños para descubrir todos los estados posibles del alma humana” (Kierkegaard, 1984a, p. 159; SKS 4, p.427). También para Haufniensis la observación ocupa un rol fundamental en la psicología, aunque esta no termine poseyendo ningún recurso experimental, mientras que en Freud la experimentación es la herramienta que le permite discutir el inconsciente especulativo de los filósofos en un terreno nuevo. Aunque Haufniensis reconoce que el método psicológico se basa en la observación, para Freud esta no escapa a la autorreferencia que le critica a los filósofos en Las resistencias contra el psicoanálisis. A diferencia del filósofo, el analista sigue el camino de la aceptación del inconsciente que le impuso la observación de distintos fenómenos. Según Assoun (1982) “[e]n El psicoanálisis y la teoría de la líbido (1923) es donde encontramos la manifestación más clara de esta oposición (entre la filosofía entendida como Weltanschauung y el psicoanálisis como Naturwissenschaft). En este escrito didáctico, Freud se propone enunciar los caracteres principales del psicoanálisis, los caracteres que no pueden pasarse por alto sin desconocer la verdadera naturaleza del psicoanálisis. No se debe a un azar el hecho de que Freud exponga como carácter final, al terminar la primera parte dedicada al psicoanálisis, su cualidad de "ciencia empírica". Freud opera esta caracterización contraponiendo el psicoanálisis a la filosofía" (pp. $50-51)$. 
Según Assoun (1982, p. 48) el concepto psicoanalítico de inconsciente permite unificar auténticamente lo psíquico, resolviendo la contradicción en la que nos abandona el concepto filosófico de inconsciente al sobrestimar simultáneamente lo consciente y lo somático. La filosofía dominante reduce el psiquismo a la conciencia.

En esto, el filósofo aparece prestando apoyo al sentido común: cuando se habla de conciencia, se sabe inmediatamente de qué se trata por la experiencia personal. La enunciación filosófica según la cual "la conciencia es ella sola lo psíquico" teoriza esta creencia. (Assoun, 1982, p. 48)

La argumentación de Assoun es concluyente en este punto. Los procesos conscientes que los filósofos defienden no forman series ininterrumpidas ni son conclusos en sí mismos; por lo tanto, es necesario admitir procesos físicos o somáticos que acompañan a lo psíquico y que son superiores a los procesos psíquicos, puesto que algunos son acompañados por procesos conscientes y otros no. De allí que haya que distinguir finalmente dos tipos de procesos, los procesos somáticos simples, no acompañados por la cualidad de la conciencia, y los procesos somáticos mixtos que comportan además la cualidad consciente.

De manera que el factor considerado principal debe terminar por considerarse auxiliar. Inversamente, esos procesos somáticos aparentemente accesorios [Parallelvorgänge o Begleitvorgänge] deberían naturalmente considerarse como "lo psíquico propiamente dicho", ahora bien, eso es aquello contra lo que "se sublevan" los filósofos. Aquí se presenta aún el organicismo como el destino normal y paradójico del conciencialismo. [...] Aquí es justamente donde interviene la posición psicoanalítica, que considera que los procesos somáticos considerados concomitantes son lo psíquico mismo. Esta curiosa fórmula significa que lo que se postuló en el conciencialismo como exterior a lo psíquico -como de orden somático- no es otra cosa que lo que pretende ser reconocido como lo psíquico mismo, esto es, el inconsciente ${ }^{16}$. (Assoun, 1982, pp. 48-49)

16 En este marco, podemos sostener que todas las dificultades que tuvo el cartesianismo para intentar la unificación entre el cuerpo y el alma, recién se resolverían con la introducción del concepto freudiano de inconsciente que es el único que permite la auténtica unificación de lo psíquico. La hipótesis cartesiana de la glándula pineal como lugar de unificación no es más que la confirmación de la sobreestimación de lo somático expresada por el modelo conciencialista. Para un análisis en una dirección diferente, véase: MacIntyre, 1982. MacIntyre concibe las teorías de Freud a medio 
5. A modo de cierre: de la teología del pecado a la psicología de la angustia

LA PSICOLOGíA NEUMÁTICA puede concebirse como una suerte de antecedente teórico de los problemas que enfrenta Freud en el terreno epistemológico a la hora de describir el psicoanálisis. Tanto Kierkegaard como Freud tienen conciencia de haber introducido una ciencia nueva, cuyo método se vincula con el carácter liberador de la palabra al que Freud denomina catártico. Mientras Haufniensis introduce la psicología como ciencia nueva en el marco de las ciencias del espíritu, Freud, sin embargo, probablemente por razones históricas vinculadas con el incipiente desarrollo del paradigma positivista, vincula la nueva ciencia con el modelo de las ciencias de la naturaleza. Tanto Haufniensis como Freud comprenden que no es posible justificar una nueva ciencia sin discutir los límites de las ciencias y en esa búsqueda ubican su nuevo descubrimiento. Freud, liga la psicología a la observación de un modo más radical que Haufniensis porque, como sostiene Assoun, concibe el psicoanálisis como un tipo de Naturwissenschaft.

A pesar de la distancia existente entre la psicología neumática y el psicoanálisis, la psicología integral, si bien no problematiza la herencia de la filosofía de la conciencia en la misma dirección que Freud, puede entenderse como antecedente de la "auténtica unificación del psiquismo" (Assoun, 1982, p. 49) operada por este. El tránsito de la filosofía del espíritu a la psicología del espíritu es el marco teórico que permite comprender la revolución teórica de Freud en términos filosóficos. Esta consiste, para decirlo con Althusser, en el descubrimiento del "continente psicológico”.

El concepto de la angustia supone un tránsito de la teología del pecado a la psicología de la angustia. En este marco, el problema del mal sigue siendo tratado en relación con la libertad, como es propio de la explicación cristiana, pero haciendo hincapié en los movimientos dialécticos de la conciencia individual al enfrentarse con su propia libertad. A diferencia del psicoanálisis, la psicología espiritualista no le otorga un rol más que filosófico o especulativo -en términos de Freud-, ficcional, podríamos decir, a la observación. Las distintas figuras que Kierkegaard presenta en su obra forman parte de un entramado ficcional que, a

camino entre dos intentos unilaterales de rectificación de la teoría cartesiana de la psique y define lo inconsciente como una reduplicación de la mente sustancial de Descartes. 
pesar de las intuiciones teóricas a partir de las cuales se las describe, no abandonan el campo estético de la literatura. La psicología neumática o de la doble voluntad posee un sentido terapéutico en el terreno de la persuasión individual como método de autoconocimiento.

La falta de relación con la observación empírica, que para el Freud que busca fundamentar el psicoanálisis se convierte en un imperativo, impide que la psicología neumática abandone de manera definitiva la filosofía de la conciencia. A pesar de la intuición inicial de El concepto de la angustia, que implica la necesidad de un nuevo ordenamiento de las ciencias para pensar el problema del mal y parece dinamitar las bases de la explicación dogmática, no deja, sin embargo, de presuponer la dogmática, ya que el problema de la libertad es planteado en relación con la caída. Esto trae dos consecuencias, por un lado, la imposibilidad del yo de fundarse a sí mismo, como se explica en La enfermedad mortal, es decir, de comprenderse plenamente a sí mismo, y por otro, a pesar de vislumbrar también los elementos opacos de la conciencia, no referirlos a lo inconsciente sino a lo involuntario.

El concepto de la angustia y La enfermedad mortal leídas conjuntamente permiten pensar el cristianismo como un fenómeno de la conciencia individual. En la segunda obra lo que define lo propiamente cristiano es el pecado. Al pensar la relación del individuo particular con el pecado, la facultad que se introduce es la voluntad. La inocencia del paganismo, que desconocía el elemento dialéctico de la voluntad, que puede tanto querer como no querer al propio yo, se sustentaba en una relación inmediata entre el cuerpo y el alma. El cristianismo, problematiza la inmediatez de esta relación a partir de la introducción del espiritu. Lo que define al yo no es su natural constitución psicofísica sino su espiritual apropiación de la misma. Esta apropiación no implica, sin embargo, un movimiento espontáneo, sino que implica una tarea de autorrealización voluntaria, que debido al carácter angustiante de la libertad no está jamás definitivamente garantizada.

Si bien en el análisis de Kierkegaard, la libertad juega un rol fundamental en la conformación de la subjetividad, esta depende de la ambigüedad del espíritu, que puede conducir al hombre tanto al bien como al mal; el límite de la finitud se vuelve patente en la voluntad. La única libertad del hombre es la de aceptar o rechazar la síntesis entre el cuerpo y el alma que a él mismo le es ajena, pues es puesta por otro. Lo demoníaco es una relación forzada con el bien, que se expresa en dos fórmulas: la pérdida somático-psíquica y la pérdida neumática de la 
libertad. Aunque el hombre se empecine en mantenerse en el mal, el bien se le impone como horizonte.

¿Qué progreso implica entonces el análisis psicológico kierkegaardiano respecto de la comprensión dogmática del pecado? La responsabilidad moral del individuo respecto a su propia libertad, cuyo origen es desconocido pero cuyos efectos, manifiestos en la angustia, le pertenecen. La constitución tripartita del hombre, como un ser conformado por el cuerpo, el alma y el espíritu, cuyo conocimiento y apropiación de sí mismo es una tarea determinada por la libertad, consolidan la imagen del hombre como un ciudadano de dos mundos. La angustia es la indicadora de la distancia, que es necesario acortar, entre el mundo de la naturaleza y el de la libertad. Kierkegaard busca la unidad de lo humano en la conciencia. El yo es el resultado de la comprensión de que lo propiamente humano no se agota, como en el caso del animal, en la inmediata relación natural entre el cuerpo y el alma, sino que implica el entendimiento del carácter inestable de esta síntesis, solo posible gracias a la introducción del tercer elemento: el espíritu, como se pone de manifiesto en La enfermedad mortal.

La pérdida de la libertad del yo es el mayor riesgo que el hombre corre, resumida en el concepto de lo demoníaco, que presenta dos formas: la pérdida somático-psíquica de la libertad, que acaece cuando el cuerpo se subleva frente a los dictámenes del alma y del espíritu produciendo un desorden en las relaciones entre los tres elementos, y la pérdida neumática de la libertad, que se produce cuando el hombre se aleja de la certeza y la interioridad, consistente en el conocimiento de que la verdad "solo existe para el individuo en cuanto él mismo la produce actuando" (Kierkegaard, 1984a, p. 173; SKS 4, p. 439) y no en la acumulación cuantitativa de conocimientos ajenos al propio yo. Es decir, el yo pierde la libertad en sentido neumático cuando en lugar de la búsqueda de la apropiación de sí mismo, se 'desrealiza' en el conocimiento objetivo.

De allí se sigue una cierta confrontación entre el conocimiento objetivo y el conocimiento subjetivo o autoconocimiento, que obliga a Kierkegaard a desarrollar distintas estrategias de comunicación indirecta con el fin de subrayar la importancia del conocimiento de sí mismo. La situación de Freud a la hora de fundamentar el psicoanálisis es distinta. Justamente con el objeto de enfrentar la especulación filosófica, busca en la observación la base empírica que requiere su nuevo descubrimiento para evitar la recaída en la ficción. 
En este sentido, el pensamiento de Kierkegaard, comprendido a partir de la formulación psicoanalítica, ha posibilitado proyectar el pasaje de la inocencia a la culpa, del que se ocupa El concepto de la angustia, en un nuevo terreno, el psicológico. No obstante, este pasaje se mantiene en los márgenes de la filosofía de la conciencia y aunque busque la unidad del yo a partir de la formulación de una psicología integral, concibe esta unidad como una tarea para la humana voluntad. Con el psicoanálisis, la psicología de la angustia que Haufniensis introduce, abandona tanto a la segunda ética como a la dogmática. Este abandono implica la profundización en el proceso de laicización de la cultura, la revalorización de la ciencia como herramienta de conocimiento frente a la filosofía especulativa y el abandono de la teoría de las facultades, propia de la teoría del conocimiento de la filosofía moderna, que Kierkegaard mantiene al discutir las relaciones entre la voluntad y el entendimiento para explicar el salto en el mal. Es probable que estos abandonos hayan permitido descubrir lo inconsciente. De allí que pensemos que el tránsito de la filosofía a la psicología que el pensamiento de Kierkegaard propicia haya posibilitado el origen del planteo psicoanalítico, aun cuando el propio Freud no haya sido consciente de que la psicología de la angustia había abonado la tierra para la siembra y el cultivo de su ciencia nueva.

Referencias

Assoun, P. L. (1980). Freud et Nietzsche. Paris: Universitaires de France.

Assoun, P. L. (1982). Freud. La filosofía y los filósofos. (Trad. A. L.Bixio). Barcelona: Ediciones Paidós.

Freud, S. (1988). Obras completas, vol. 15. Buenos Aires: Hyspamerica.

González, D. (2001). "The Triptych of Sciences in the Introduction to The Concept of Anxiety”. En: N. J. Cappelørn, H. Deuser, J. Stewart \& C. T. Fink. (Eds.), Kierkegaard Studies (pp. 15 - 42) Berlin, New York: Walter de Gruyter.

Grøn, A. (1998). "La ética de la repetición”. Enrahonar, 29, pp. 35-45.

Kierkegaard, S. (1997-2009). Søren Kierkegaard Srifter. Copenhague: Gad.

Kierkegaard, S. (1984a). El concepto de la angustia. Madrid: Orbis.

Kierkegaard, S. (1984b). La enfermedad mortal. Madrid: Sarpe.

Löwith, K. (1968). De Hegel a Nietzsche. Buenos Aires: Sudamericana. 
MacIntyre, A. (1982). El concepto de lo inconsciente. Buenos Aires: Amorrortu Editores.

Negre Rigol, M. (1998). "Fundamentación ontológica del sujeto en Kierkegaard”. Anuario Filosófico, 21(1), pp.51-72.

Tauber, A. (2014). Freud, el filósofo reticente. España: Avarigani Editores.

Taubes, J. (2007). Del culto a la cultura: elementos para una critica de la razón histórica. Buenos Aires: Katz.

Valls Plana, R. (1994). Del yo al nosotros. Lectura de la Fenomenología del espíritu de Hegel. Barcelona: PPU. 